\title{
Safety Assessment on the Self-Berthing /Unberthing of a 1000TEU Ship at Japanese Ports
}

\author{
Jia-zhao Liu ${ }^{1,}$ a and Xing-tao Zhang ${ }^{2, \text { b }}$ \\ ${ }^{1}$ Qingdao Ocean Shipping Mariners College, Qingdao 266071, China \\ 2 Shandong Maritime Safety Administration, Qingdao 266002, China \\ aliujz@126.com, b capt_zhang@126.com
}

\begin{abstract}
Keywords: 1000 TEU ship, Berthing/unberthing, Analytical Hierarchy Process, Fuzzy Mathematics, Mathematical Model

Abstract. Berthing/unberthing operation is a ship's transformation from one status to the other through the integrated cooperation with crew, ship and the environment. Each process of the berthing/unberthing is complex and unduplicated and its safety is hard to be assessed through traditional mathematical and precise quantified method. In order to quantify the safety of a $1000 \mathrm{TEU}$ ship's berthing / unberthing at Japanese ports without tugs and pilots, we apply systems engineering and analytical hierarchy process, set up safety assessment indexes, determine the weight distribution and subordinate degree of each index, establish multiple fuzzy comprehensive evaluation mathematical model and conduct model validation in ship's handling practice. It proves that the model is efficient and reliable.
\end{abstract}

\section{Introduction}

The self piloting, berthing and unberthing of container lines are regarded as the "sole point[1]" for reducing the cost and increasing the profit in the coastal and China-Japan lines. S shipping company has 32 self owned container vessels and 27 are 1000 TEU vessels, with their gross tonnage less than 10000, length less than 150 meters and full load of 1000 TEU's. This vessel type suits the basic requirements for applying self berthing and unberthing in the main ports as Tokyo, Isewan and Osaka bays[2]. This paper takes reference from this vessel type to probe into the safety of masters in directing their vessels for berthing and unberthing without the assistance of pilots and tow boats, excluding the piloting and towing assistance.

\section{Establishing the index system for safety evaluation}

The establishment of a set of perfect, rational and scientific index system for safety evaluation shall follow the principle of completeness, independence, compatibility, operability and simplicity. The marine traffic engineering science integrates the human, ship and environment into one system in the studies of marine traffic[3] and the safety evaluation of the self berthing and unberthing of 1000 TEU ships at Japanese ports shall also take into account the three elements. Therefore, the three elements are the first level index.

The human element includes the second level of index of master ability, master experience and team support. Master ability refers to his core competences of ship maneuver, decision-making, direction, response to risks, reaction to accidents and safety awareness[4]. The master abilities determine the adequacy and response to the planning of berthing and unberthing. Master experience refers to that of the master in navigating and maneuvering the vessel type in self berthing and unberthing, entering and departing from Japanese ports, which directly influences the scientific planning of berthing and unberthing. Japanese ports require that, when deciding self maneuvering of the ship in entering and leaving ports in restricted areas without applying for pilot, the master shall have the experience of at least 4 times of navigating the ship of similar tonnage in the area[2]. Team support refers to the response and support from the ship departments including the bridge to the berthing and unberthing operation and it directly influences the extent of the execution of berthing 
and unberthing plan. The Japanese stevedores and standardized cable operation render little influence on the safety evaluation of berthing and unberthing and are out of consideration here.

The ship element refers to the second level of three items of ship engine situation, loading of the ship and ship floating state. The ship engine situation refers to the response speed of the main engine, bow thrust and berthing equipment, etc.

The environmental elements include three indexes of wind current, berthing and channel situations. While the wind current refers to the levels and its co-relationship towards the ship's heading, the influence of wind and current is co-related and inseparable to the safe berthing and unberting. Therefore, we cannot separate the influence of wind and current and the integrated evaluation of the influence of wind and current on ship safety carries greater scientific and operational senses. The berthing situation refers to the length of the berthage and the existence of other ships berthing, which directly influences the strictness of the ship length to berthing angles and the control of the residual speed. The berthing channel includes the facts of the angle between the channel and berthage and the area and bottom quality of the brake water and head of water. The berthing channel directly influences the choice of maneuver plan by the ship master, such as maintaining the course, control of the residual speed, head of water and operation of anchor, etc.

In summary, the classification of the evaluation indexes for the safe berthing of a 1000 TEU ship berthing a Japanese port forms a ladder structure[5] as follows in Table 1.

Table 1 Evaluation index

\begin{tabular}{|c|c|c|c|c|c|c|c|c|}
\hline \multicolumn{3}{|c|}{$u_{1}$ human } & \multicolumn{3}{|c|}{$u_{2}$ ship } & \multicolumn{3}{|c|}{$u_{3}$ environment } \\
\hline$u_{11}$ & $u_{12}$ & $u_{13}$ & $u_{21}$ & $u_{22}$ & $u_{23}$ & $u_{31}$ & $u_{32}$ & $u_{33}$ \\
\hline 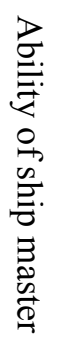 & 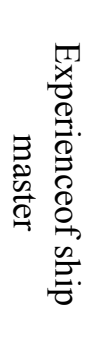 & 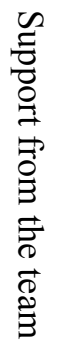 & 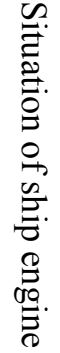 & 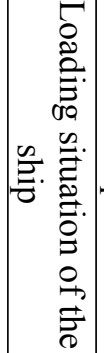 & 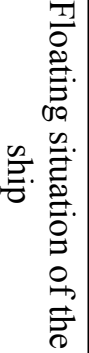 & $\begin{array}{l}\vdots \\
\vdots \\
2 \\
0 \\
0 \\
2 \\
\vdots \\
\vdots \\
0\end{array}$ & 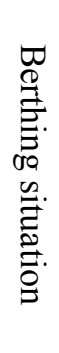 & 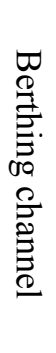 \\
\hline
\end{tabular}

\section{Establishing the integrated evaluation model}

Establishing the elements sets

The determination of element sets is key to the fairness and reasonableness of fuzzy integrated evaluation. In accordance with the evaluation indexes determined by the foregoing analysis, the element sets that can be concluded is as follows:

$U=\left\{\right.$ human $u_{1}$, ship $u_{2}$,environment $\left.u_{3}\right\}$;

$u_{1}=$ ability of ship master $u_{11}$, experience of ship master $u_{12}$, support from the team $\left.u_{13}\right\}$;

$u_{2}=\left\{\right.$ situation of ship engine $u_{21}$,loading situation of the ship $u_{22}$,floating situation of the ship $\left.u_{23}\right\}$;

$u_{3}=\left\{\right.$ wind and current $u_{31}$, situation of berthing $u_{32}$, berthing channel $\left.u_{33}\right\}$ 。

Establishing evaluation sets

When categorizing the evaluation sets into five levels, using $V=\left\{v_{1}, v_{2}, v_{3}, v_{4}, v_{5}\right\}=\{-2,-1,0,1,2\}$ to indicate the corresponding safety level of berthing and unberthing operation, the digits correspond to the levels of evaluation as (very safe, safe, general, dangerous, very dangerous).

Determining the subordinating degrees of the evaluation factors

In the evaluation of the hazard degree, whether it is able to reasonably determine the membership function directly influences the rationality of the evaluation results[6]. When adopting the expert investigation methods and rendering investigation on 10 masters handling the same container vessels sailing in Japanese routes and the subordinating degrees are determined of the evaluation indexes[5], as is shown in Table 10. 
When determining the subordinating degree of the masters' abilities, it is reasonable to classify them into "superior," "high," "general," "low." "Superior" refers to 5 years working as a master, with rich ship maneuvering experience and good records, without accidents. "Good" refers to 3 years working as a master, with good record and without accidents, or one working as a master for 5 years, with general record and minor accidents. "General" refers to one working as a master for 1 year, with good record, or long time work experience but general record. "Low" refers to one capable of a master's quality and capability, but with inadequate experience or other defects. The subordinating degrees acquired by the investigation are shown as Table 2 .

Table 2 Subordinate degree of Captain' ability
\begin{tabular}{|c|c|c|c|c|c|}
\hline Dbility & -2 & -1 & 0 & 1 & 2 \\
\hline Superior & $9 / 10$ & $1 / 10$ & $0 / 10$ & $0 / 10$ & $0 / 10$ \\
\hline High & $1 / 10$ & $8 / 10$ & $1 / 10$ & $0 / 10$ & $0 / 10$ \\
\hline General & $0 / 10$ & $0 / 10$ & $4 / 10$ & $5 / 10$ & $1 / 10$ \\
\hline Low & $0 / 10$ & $0 / 10$ & $0 / 10$ & $1 / 10$ & $9 / 10$ \\
\hline
\end{tabular}

When determining the subordinating degree of the master's experience, we classify it into rich, good, general and inadequate. "Rich" refers to one with 1 year and more of directing on self reliance the berthing and unberthing for the ship type, going through the changes of seasons, familiar with the ship, crew members, port, cargo, hydrology and climate, etc. "Good" refers to one with less than 1 year of directing on self reliance the berthing and unberthing for the ship type, not fully experiencing the changes of seasons,, with inadequate experience in hydrology and climate. "General" refers to one trained by the S company, familiar with crew members, ship, environment and with little experience in directing the berthing, or one employed from outside, unfamiliar with the crew members, but with experience in berthing for the ship type sailing on Japanese routes, or one with long working process, but with general work record or unclear about the work disappointed with the work. "Inadequate" refers to one without the working experience onboard the ship type sailing on Japanese routes, with little experience in directing on independently the ship type for berthing and unberthing. The subordinating degrees acquired by the investigation are shown as Table 3.

Table 3 Subordinate degree of Captain's experience
\begin{tabular}{|c|c|c|c|c|c|}
\hline Experience Degree & -2 & -1 & 0 & 1 & 2 \\
\hline Rich & $8 / 10$ & $2 / 10$ & $0 / 10$ & $0 / 10$ & $0 / 10$ \\
\hline Good & $0 / 10$ & $6 / 10$ & $3 / 10$ & $1 / 10$ & $0 / 10$ \\
\hline General & $0 / 10$ & $1 / 10$ & $5 / 10$ & $4 / 10$ & $0 / 10$ \\
\hline Inadequate & $0 / 10$ & $0 / 10$ & $0 / 10$ & $2 / 10$ & $8 / 10$ \\
\hline
\end{tabular}

When determining the subordinating degree of the team support, we classify it into "superior," "good," "general" and "inadequate." "Superior" refers to good understanding, implementation and facilitation of the team. "Good" refers to good understanding, implementation and facilitation. "General" refers to being bale to understand, implement and facilitate. "Inadequate" refers to deficit in understanding, implementing and facilitation the purpose of the master. The cooperation time and experience between the master and the team are important indexes for determining the degree of cooperation. The subordinating degrees acquired by the investigation are shown as Table 4 .

Table 4 Subordinate degree of Team's support

\begin{tabular}{|c|c|c|c|c|c|}
\hline Degree & -2 & -1 & 0 & 1 & 2 \\
\hline Team support & $9 / 10$ & $1 / 10$ & $0 / 10$ & $0 / 10$ & $0 / 10$ \\
\hline Superior & $1 / 10$ & $9 / 10$ & $0 / 10$ & $0 / 10$ & $0 / 10$ \\
\hline Good & $0 / 10$ & $0 / 10$ & $1 / 10$ & $8 / 10$ & $1 / 10$ \\
\hline General & $0 / 10$ & $0 / 10$ & $0 / 10$ & $1 / 10$ & $9 / 10$ \\
\hline
\end{tabular}

When determining the subordinating degree of ship machine's status, we classify it into "superior," "good," "general" and "inadequate." "Superior" refers to the status that all the equipment is in good state, ready for use and is able to satisfy the needs for emergency operation. "Good" refers 
to the fact that all the equipment is well maintained and is ready for use. "General" refers to the fact that all the equipment can be correctly operated and can satisfy the basic needs. Inadequate" refers to the fact that some of the equipment needs special preparation or has special requirements and certain equipment bears deficit and brings forth difficulty on account of the lack of spare parts. The subordinating degrees acquired by the investigation are shown as Table 5.

Table 5 Subordinate degree of Ship machine's status
\begin{tabular}{|c|c|c|c|c|c|}
\hline Degree & -2 & -1 & 0 & 1 & 2 \\
\hline Machines & & & & & \\
\hline Superior & $8 / 10$ & $2 / 10$ & $0 / 10$ & $0 / 10$ & $0 / 10$ \\
\hline Geod & $0 / 10$ & $8 / 10$ & $2 / 10$ & $0 / 10$ & $0 / 10$ \\
\hline Inadequate & $0 / 10$ & $0 / 10$ & $3 / 10$ & $7 / 10$ & $0 / 10$ \\
\hline
\end{tabular}

When determining the subordinating degree of ship loading situation, we classify the loading as empty, 1/3 load, 1/2 and full load. The subordinating degrees acquired by the investigation are shown as Table 6 .

Table 6 Subordinate of Ship's loading

\begin{tabular}{|c|c|c|c|c|c|}
\hline Load Degree & -2 & -1 & 0 & 1 & 2 \\
\hline Empty & $8 / 10$ & $2 / 10$ & $0 / 10$ & $0 / 10$ & $0 / 10$ \\
\hline $1 / 3$ Load & $1 / 10$ & $8 / 10$ & $1 / 10$ & $0 / 10$ & $0 / 10$ \\
\hline $1 / 2$ Load & $0 / 10$ & $0 / 10$ & $3 / 10$ & $7 / 10$ & $0 / 10$ \\
\hline Full load & $0 / 10$ & $0 / 10$ & $0 / 10$ & $2 / 10$ & $8 / 10$ \\
\hline
\end{tabular}

When determining the subordinating degree of ship's floating state, we classify it into 4 situations in accordance with the trim $t$. The subordinating degrees acquired by the investigation are shown as Table 7 and the unit of $\mathrm{t}$ is $\mathrm{m}$.

Table 7 Subordinate degree of Ship's floating state
\begin{tabular}{|c|c|c|c|c|c|}
\hline Leaning Degree & -2 & -1 & 0 & 1 & 2 \\
\hline $0>\mathrm{t}>-1$ & $8 / 10$ & $2 / 10$ & $0 / 10$ & $0 / 10$ & $0 / 10$ \\
\hline$-1 \geq \mathrm{t}$ & $1 / 10$ & $8 / 10$ & $1 / 10$ & $0 / 10$ & $0 / 10$ \\
\hline $1>\mathrm{t} \geq 0$ & $0 / 10$ & $0 / 10$ & $4 / 10$ & $6 / 10$ & $0 / 10$ \\
\hline $\mathrm{t} \geq 1$ & $0 / 10$ & $0 / 10$ & $0 / 10$ & $2 / 10$ & $8 / 10$ \\
\hline
\end{tabular}

When wind force is 6 degree or current is 4 knots, the risk for independent berthing and unberthing is dangerous, therefore it is suggest to apply for assistance of tugging. As a result, when determining the subordinating degree of wind effect, given the consideration of the both influences, we classify it into 4 situations, favored, top flow 1 2 knots, top wind 3 4 degrees; good, top flow 2 4 knots, top wind 1 2 degrees; general, no current, no wind; severe, downstream 1 2 knots, crosswind or tailwind. The subordinating degrees acquired by the investigation are shown as Table 8 .

Table 8 Subordinate degree of Wind effect

\begin{tabular}{|c|c|c|c|c|c|}
\hline Wind effect & -2 & -1 & 0 & 1 & 2 \\
\hline Favored & $8 / 10$ & $2 / 10$ & $0 / 10$ & $0 / 10$ & $0 / 10$ \\
\hline Good & $0 / 10$ & $1 / 10$ & $8 / 10$ & $1 / 10$ & $0 / 10$ \\
\hline General & $0 / 10$ & $0 / 10$ & $4 / 10$ & $6 / 10$ & $0 / 10$ \\
\hline Severe & $0 / 10$ & $0 / 10$ & $0 / 10$ & $2 / 10$ & $8 / 10$ \\
\hline
\end{tabular}

When determining the subordinating degree of berthing situation, we classify it into "superior," "good," "general" and "bad." "Superior" refers to the situation of no ship in front and behind the berthing place and with adequate length; "good" refers to the situation that there are ship either in front or behind, with adequate length; "general" refers to the situation that there are ships in front or behind, with limited length and "bad" refers to the situation that there are ships in front or behind and with limited length. The subordinating degrees acquired by the investigation are shown as Table 9. 
Table 9 Subordinate degree of Berth situation

\begin{tabular}{|c|c|c|c|c|c|}
\hline Dituation & -2 & -1 & 0 & 1 & 2 \\
\hline Superior & $8 / 10$ & $2 / 10$ & $0 / 10$ & $0 / 10$ & $0 / 10$ \\
\hline Good & $0 / 10$ & $7 / 10$ & $3 / 10$ & $0 / 10$ & $0 / 10$ \\
\hline General & $0 / 10$ & $0 / 10$ & $6 / 10$ & $4 / 10$ & $0 / 10$ \\
\hline Bad & $0 / 10$ & $0 / 10$ & $0 / 10$ & $2 / 10$ & $8 / 10$ \\
\hline
\end{tabular}

When determining the subordinating degree of the berthing channel, we classify the situation into "superior," "good," "general" and "bad." "Superior" refers to the situation of adequate water area and direct berthing is feasible; "good" refers to the situation that there is adequate water area but turning and backing is necessary for berthing; "general" refers to the situation that the water area is limited but direct berthing is feasible; while "bad" refers to the situation that the water area is limited and turning and backing is necessary for berthing. The subordinating degrees acquired by the investigation are shown as Table 10.

Table 10 Subordinate degree of Berth channel
\begin{tabular}{|c|c|c|c|c|c|}
\hline Degree & -2 & -1 & 0 & 1 & 2 \\
\hline Channel & & & & & \\
\hline Superior & $8 / 10$ & $2 / 10$ & $0 / 10$ & $0 / 10$ & $0 / 10$ \\
\hline Good & $0 / 10$ & $8 / 10$ & $2 / 10$ & $0 / 10$ & $0 / 10$ \\
\hline General & $0 / 10$ & $0 / 10$ & $7 / 10$ & $3 / 10$ & $0 / 10$ \\
\hline Difficult & $0 / 10$ & $0 / 10$ & $0 / 10$ & $2 / 10$ & $8 / 10$ \\
\hline
\end{tabular}

Determining the weight of the evaluating factors

The term weight refers to the contribution of the factors to the general target and only rational distribution of index weight will it be able to acquire the objective evaluation effect[7-8]. We made use of the analytical hierarchy process[9-10] and invited 10 masters commanding the same type of container vessels sailing on Japanese routes to make the pair comparison on the importance of the evaluation factors. The following judgment matrix is acquired on induction and arrangement and the weight of the factors is acquired on calculation[5].

(1) Weight of human, ship and environment

Table 11 Weight distribution table

\begin{tabular}{|c|c|c|c|}
\hline Judgment matrix & human & Ship & Environment \\
\hline human & 1 & 7 & 3 \\
\hline Ship & $1 / 7$ & 1 & $1 / 2$ \\
\hline Environment & $1 / 3$ & 2 & 1 \\
\hline
\end{tabular}

The judgment matrix is acquired as follows in accordance with the steps of sum product[11].

$$
\left[\begin{array}{lll}
0.6774 & 0.7000 & 0.6667 \\
0.0967 & 0.1000 & 0.1111 \\
0.2258 & 0.2000 & 0.2222
\end{array}\right]
$$

Its feature vector $W=A=[0.68140 .10260 .2160]$, maximum characteristic root $\lambda_{\max }=3.0026, \mathrm{CR}=$ $0.0022<0.1$, which comply with the consistency check.

(2) The weight of human factor

Table 12 Weight distribution table of Human

\begin{tabular}{|c|c|c|c|}
\hline Judgment matrix & Master's ability & Master's experience & Team support \\
\hline Master's ability & 1 & 7 & 5 \\
\hline Master's experience & $1 / 7$ & 1 & $1 / 3$ \\
\hline Team support & $1 / 5$ & 3 & 1 \\
\hline
\end{tabular}

The judgment matrix is acquired as follows in accordance with the steps of sum product.

$\left[\begin{array}{lll}0.7447 & 0.6364 & 0.7985 \\ 0.1064 & 0.0909 & 0.0526 \\ 0.1489 & 0.2727 & 0.1579\end{array}\right]$


Its feature vector $W=A_{I}=\left[\begin{array}{lll}0.7235 & 0.0833 & 0.1932\end{array}\right]$, maximum characteristic root $\lambda_{\max }=3.0658$, $\mathrm{CR}=0.0567<0.1$, which comply with the consistency check.

(3) The weight of ship factor

Table 13 Weight distribution table of Ship

\begin{tabular}{|c|c|c|c|}
\hline Judgment matrix & Ship engine & Loading & Floating \\
\hline Ship engine & 1 & 7 & 9 \\
\hline Loading & $1 / 7$ & 1 & 3 \\
\hline Floating & $1 / 9$ & $1 / 3$ & 1 \\
\hline
\end{tabular}

The judgment matrix is acquired as follows in accordance with the steps of sum product.

$$
\left[\begin{array}{lll}
0.7975 & 0.8400 & 0.6923 \\
0.1139 & 0.1200 & 0.2308 \\
0.0886 & 0.0400 & 0.0769
\end{array}\right]
$$

Its feature vector $W=A_{2}=\left[\begin{array}{lll}0.7766 & 0.1549 & 0.0685\end{array}\right]$, maximum characteristic root $\lambda_{\max }=3.0821$, $\mathrm{CR}=0.0708<0.1$, which comply with the consistency check.

(4) The weight of environment factor

Table 14 Weight distribution table of Environment

\begin{tabular}{|c|c|c|c|}
\hline Judgment matrix & Wind and current & Berthing place & Berthing channel \\
\hline Wind and current & 1 & 7 & 8 \\
\hline Berthing place & $1 / 7$ & 1 & 2 \\
\hline Berthing channel & $1 / 8$ & $1 / 2$ & 1 \\
\hline
\end{tabular}

Structural judgment matrix:

$$
A=\left[\begin{array}{ccc}
1 & 7 & 8 \\
1 / 7 & 1 & 1 / 2 \\
1 / 8 & 2 & 1
\end{array}\right]
$$

The judgment matrix is acquired as follows in accordance with the steps of sum product.

$$
\left[\begin{array}{lll}
0.7887 & 0.8235 & 0.7273 \\
0.1127 & 0.1176 & 0.1818 \\
0.0986 & 0.0588 & 0.0909
\end{array}\right]
$$

Its feature vector $W=A_{3}=\left[\begin{array}{lll}0.7798 & 0.1374 & 0.0828\end{array}\right]$, maximum characteristic root $\lambda_{\max }=3.0353$, $\mathrm{CR}=0.0304<0.1$ which comply with the consistency check.

Establishing the safety evaluation model

In accordance with the description of the safety index system for ships' self berthing and unberthing along Japanese docks, the evaluation system is a second class assessment, as:

$$
B=A \circ R=A \circ\left[\begin{array}{ccc}
A_{1} & \circ & R_{1} \\
A_{2} & \circ & R_{2} \\
A_{3} & \circ & R_{3}
\end{array}\right]
$$

In the formula, $R_{1} 、 R_{2} 、 R_{3}$ refer to the second class evaluation index subordinating degree matrix human, ship and environment. In accordance with the special situation of the factors of human, ship and environment of the dock to be berthed along, choose the suitable corresponding subordinating degree from the table and compose the corresponding determination matrix. When the determination matrix is fixed, we can calculate via the fuzzy mapping the safety evaluation result $B$ for the 1000TEU ship to berth along a Japanese dock.

\section{Modeling verification}

In order to verify the degree of fit between the evaluation model and the practical situation, the authors intend to use the practical process and result of a certain S.Y ship berthing the South Pier of 
Yokohama at 0600 , a certain day in 2007. Based on the subordinating degree function and model operator suggested at 2.3, we get the follow result.

$$
\begin{aligned}
& R_{1}=\left[\begin{array}{ccccc}
1 / 10 & 8 / 10 & 1 / 10 & 0 & 0 \\
0 & 6 / 10 & 3 / 10 & 1 / 10 & 0.1 \\
0 & 0 & 0 & 0.1 & 0.9
\end{array}\right] \\
& R_{2}=\left[\begin{array}{ccccc}
1 / 10 & 8 / 10 & 1 / 10 & 0 & 0 \\
0 & 6 / 10 & 3 / 10 & 1 / 10 & 0.1 \\
0 & 0 & 0 & 0.1 & 0.9
\end{array}\right] \\
& R_{3}=\left[\begin{array}{ccccc}
1 / 10 & 8 / 10 & 1 / 10 & 0 & 0 \\
0 & 6 / 10 & 3 / 10 & 1 / 10 & 0.1 \\
0 & 0 & 0 & 0.1 & 0.9
\end{array}\right]
\end{aligned}
$$

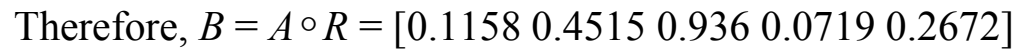

Dispose of the evaluation factor using the weight mean method,

$$
v=\frac{\sum_{j=1}^{m} b_{j} v_{j}}{\sum_{j=1}^{m} b_{j}}=-0.0767,-1<v<0 \text {; }
$$

The evaluation result is between very safe and general, close to general.

In face of the severe influence of the present wind and current, the master adopts the following measures to improve the safety of berthing, (1) Inform the engine room for emergency engine; (2) Inform the chief officer to prepare the both anchors for immediate use; (3) Inform the head and stern to prepare the mooring cables ahead of time; (4) Try the utmost the lower the speed ahead of the time and use fast speed when time is suitable and keep the head direction along the wind with the same line; (5) 300 meters before berthing and 50 meters along, throw the short anchor to reduce speed; (6) 50 meters away from the berth, let go of the anchor chain for 5 knots deck with force to best control the speed and course; (7) Use Japanese mooring boat to rapidly send the cable to the bitt, with head and stern cooperating in parallel rope twisting to send the ship to the dock in the parallel manner and avoid any angle with the wind direction.

The result is successful berthing, but with multi manipulation of the engine, as many as 40 times, which is close to the calculation of the mathematical model.

\section{Conclusion}

On the qualitative and quantitative analysis on the factors that influence the safe berthing of a $1000 \mathrm{TEU}$ vessel, the paper makes use of fuzzy integrated evaluation for the result of safe evaluation to assist the master and shipping company to make safe and correct decision. Although the evaluation indexes and model are based on the certain crew members, ship and port of a certain company with strong typical characteristics, the results for the other ships, especially those sailing on Japanese routes carry great value for reference.

\section{Acknowledgements}

This work was financially supported by COSCO research project (2014-1-H-004). 


\section{References}

[1] Lian Xu, "COSCO-Shipping Makes New Record in Coastal Liner Operation", COSCO Ocean Management, [J].2013, (9) : 30-31

[2] Yue-ming Lu, "Japanese Pilotage Industry on Water Transportation", Water Transportation Management, [J].2011, $33(9): 36-37$

[3] Zhao-lin Wu, "Ocean Transportation Engineering," [M]. Dalian, Dalian Maritime University Press, 1993.

[4] Guo-feng Zhu, "Analysis Questionnaire on the Competence of Masters," China Navigation, $[\mathrm{J}] .2005,63(2): 22-27$

[5] Xing-tao Zhang, "Studies on the Safety Evaluation for the Self Berthing and Unberthing of a Certain Container Vessel," [D]. Dalian, Dalian Maritime University Press, 2014

[6] Ren-yu Zhao, "Fuzzy Integrated Evaluation on the Dangerous degree in Water Transportation," China Navigation, [J]. 1997, 41 (2) : 40-45

[7] Zhong-zhou Fan, Zhao-lin Wu, Hong-bin Xie, et al, "Fuzzy Multiple Criteria Optimization Method in Chengshan Jiao Routeing Scheme", [J]. China Navigation. 2013， 36 (2):50-54

[8] Yan-jun Pang, Kai-di Liu, Bo-wen Zhang, "Determination Method on the Objective Weight Index for Integrated Evaluation System," [J]. System Engineering Theory and Practice, 2001（8） : 37-42

[9] Zhen-pu Dong, "Mathematical modeling method and Practice", [M]. Beijing, National Defense Industry Press, 2006.

[10] Jia-zhao Liu, Yu-zhu Zhu, "The Fuzzy and Integrated Evaluation in the Competence of Routeing,”[J]. Journal of Dalian Maritime University, 2006，32（4） : 65-68

[11] Hang Liu, "Two approximate calculation method in the analytic hierarchy process" Journal of Nanjing College of Posts and Telecommunications, [J].1987，7（4）: 135-139 